\title{
Growth Performance and Condition Factor of Juvenile Milkfish (Chanos chanos) Cultured in a Marine Pen in Relation to Body Size and Temperature
}

\author{
Masashi KODAMA ${ }^{1 *}$, Rose Ann DIAMANTE ${ }^{2}$, Nerissa D. SALAYO ${ }^{2}$, \\ Raisa Joy G. CASTEL ${ }^{2}$ and Joemel G. SUMBING ${ }^{3}$ \\ ${ }^{1}$ Research Management Department, Headquarters, Japan Fisheries Research and Education Agency, \\ Yokohama, Japan \\ ${ }^{2}$ Aquaculture Department, Southeast Asian Fisheries Development Center (SEAFDEC/AQD), \\ Tigbauan, Iloilo, Philippines \\ ${ }^{3}$ Graduate School of Urban Innovation, Yokohama National University, Yokohama, Japan
}

\begin{abstract}
The growth performance and condition factor (CF) of milkfish (Chanos chanos) in relation to body size and temperature were investigated in a shallow marine pen culture system in coastal waters of the Philippines. Three common models were tested to determine the best-fit model for the growth of milkfish, and the logistic model was found to be best for both weight-based and length-based growth. Daily specific growth rate in weight $\left(D S G R_{w}\right)$ and length $\left(D S G R_{L}\right)$ were positively correlated with water temperature, while both $D S G R_{w}$ and $D S G R_{L}$ were correlated negatively with the size of the fish, which supported the fit of the growth model. CF of milkfish exhibited a positive correlation with the feed conversion ratio and significant seasonal variations. The ratio was lower in the fast growth season (dry season) than in the slow growth season (rainy season). By integrating these controversial findings, we were able to posit that low temperature and inefficient feeding makes 'fat' fish and vice versa. This may be explained by changes in proximate body composition (e.g., protein and water content) and the change in metabolic rate brought about by different water temperatures.
\end{abstract}

Discipline: Fisheries

\section{Introduction}

Milkfish (Chanos chanos) are an economically important cultured fish in Southeast Asia. They are distributed in the tropical and subtropical areas centered in the Indo-Pacific, at water temperatures $>20^{\circ} \mathrm{C}$, as defined by the winter surface isotherms (Bagarinao 1991). In the Philippines, milkfish are one of the major contributors to aquaculture production, at levels comparable to those of seaweed, with an annual production of 411 metric tons in 2017 (Philippines Statistics Authority). Their euryhaline nature enables milkfish to grow in multiple different systems; they are amenable to fresh water (e.g., lakes), brackish water (e.g., ponds), and marine systems (e.g., coastal areas).

Growth information on cultured fish is important for planning and managing aquaculture. Indicators such as specific growth rate (SGR) and condition factor (CF) provide basic information for evaluating the specific conditions necessary for growing the organism. Specific growth rate quantitatively measures the increase in cell mass per unit of time and is often used as a primary method in presenting data when comparing across different ages or populations, or in describing shifts that occur during the life of individuals (Weatherley \& Gill 1987). CF is a parameter that is estimated based on the length-weight data that signifies the well-being of the fish through population success by its influence on growth, reproduction, and survival (Hossain et al. 2006, as cited in Biswas et al. 2011). These factors are dependent on environmental conditions as outdoor systems are prone to daily and seasonal environmental fluctuations. Most studies on milkfish deal with the influence of salinity and how changes in salinity alter the adaptations, metabolisms, and growth of fish (Hanke et al. 2019). Although milkfish are ectothermic and affected by 
temperature, few studies have focused on temperature as a stressor in milkfish aquaculture.

For commercially important aquatic organisms, several growth models (linear, logistic, Gompertz, von Bertalanffy, Richards, etc.) have been proposed and applied not only for fish (Dumas et al. 2010, Pauly et al. 1993) but also for invertebrates (Rogers-Bennet et al. 2007, Watanabe et al. 2014), given their usefulness for aquaculture planning and management.

Suitability of the growth model depends on the species; however, information on the growth performance, particularly of milkfish, is very limited despite its economic importance. The growth curve of milkfish is approximated by linear regression (FAO, Aquaculture Feed and Fertilizer Resources Information System), along with the relationship between growth and food consumption (Sumagaysay 1994). And although the feed guide provided by some feed companies in the Philippines (e.g., TATEH) is size dependent, implying that the feed rate decreases as the fish grows and that the growth rate follows the same pattern, there is no existing nonlinear model proposed for milkfish.

In this study, common models were tested to determine the best-fit model for milkfish cultured in a marine pen, and the controlling factors of specific growth rate and condition factor were investigated.

\section{Materials and methods}

\section{Experimental setup and evaluation of growth performance}

The study was conducted during experimental farming of milkfish in the coastal waters of Baranggay Pandaraonan, Nueva Valencia, Guimaras, in the Philippines from August 2015 to January 2018 in a series of experimental runs. Two runs were conducted during the dry season (Run 1 and Run 3) and two runs were conducted during the rainy season (Run 2 and Run 4). Using temperature and rainfall as the basis, the dry season in the Philippines refers to low rainfall that typically extends from December to May with mean temperature of $28.3^{\circ} \mathrm{C}$ in the warmest month, whereas the wet season is characterized by rainfall that typically extends from June to November with mean temperature of $25.5^{\circ} \mathrm{C}$ in the coolest month (PAGASA, Philippines). Seasonal changes characterized by the changes in temperature and weather conditions have direct and indirect effects on aquaculture. Changes in temperature and rainfall patterns and the effects thereof on salinity and oxygen can affect the physiological processes in the farmed organism, thereby affecting its growth and then the productivity of the system.
Juvenile milkfish acquired from a local pond in Guimaras were stocked in two pens with an area of 150 $\mathrm{m}^{2}$ and $162 \mathrm{~m}^{2}$, respectively, except during Run 1 (where only one pen with an area of $144 \mathrm{~m}^{2}$ was used). Stocking densities vary depending on the availability of the fingerlings, but ranged from 20.9 to $33.9 \mathrm{pcs} / \mathrm{m}^{2}$. The initial average body weight (ABW) and average body length (ABL) ranged from $15.8 \mathrm{~g}$ to $77.2 \mathrm{~g}$ and $9.4 \mathrm{~cm}$ to $16.2 \mathrm{~cm}$, respectively. Table 1 presents more detailed information. The fish were fed commercial pellets (Oversea Feeds Corporation, Philippines) at a rate depending on body size: as the average body weight increases, the given feed rate decreases. Temperature data were obtained by a data logger (HOBO Onset, USA) installed inside the pens. The average water temperature between Run 1 and Run 3 was higher at $30.6^{\circ} \mathrm{C}$, whereas Run 2 and Run 4 had lower temperatures at $29.7^{\circ} \mathrm{C}$ and $28.8^{\circ} \mathrm{C}$, respectively. From the fish population, $10 \%$ of the group was anesthetized using 2-phenoxyethanol, and then sampled for body weight $(\mathrm{g})$ and body length $(\mathrm{cm})$ measurements. Sampling was done from the beginning and then every four weeks until harvest. The daily specific growth rate in weight $\left(D S G R_{w}\right)$ was calculated as:

$$
\operatorname{DSGR}_{w}(\%)=100\left(W_{t 2}-W_{t 1}\right) /\left(t_{2}-t_{1}\right) W_{t 1}
$$

Where $t_{2}$ is the sampling day, $t_{1}$ is the previous sampling day, $W_{t 2}$ is the weight on the sampling day, and $W_{t 1}$ is the weight on the previous sampling day. This also applies to length $\left(D S G R_{L}\right)$ with respect to $L_{t 2}$ and $L_{t 1} . S G R_{w}$ was calculated as:

$$
S G R_{w}(\%)=100\left(\exp \left(\frac{\ln \left(W_{f}\right)-\ln \left(W_{i}\right)}{D O C}-1\right)\right)
$$

Where $W_{f}$ is the final weight, $W_{i}$ is the initial weight, and DOC is days of culture. This also applies to length $\left(S G R_{L}\right)$ with respect to $L_{f}$ and $L_{i}$. $S G R_{w}$ and $S G R_{L}$ were used to examine the relationships between condition factor measurements, $W_{t 2}$ was set to values from the final sampling, and $W_{t 1}$ was set to the initial weight at $\mathrm{DOC}=$ 0 . Fulton's condition equation of $K=100(A B W) /(A B L)^{3}$ was used to determine the condition factor $(\mathrm{CF})$ of the fish, and the feed conversion ratio (FCR) was calculated by dividing the weight gain of the fish by the given feed.

\section{Growth model fitting}

Three common models-linear, logistic, and Gompertz-were tested to describe the growth performance of milkfish. The tree models for weight $W$ at time $t(=\mathrm{DOC})$ are expressed as: 
Linear model: $W(t)=a t+Y$

Logistic model: $W(t)=\frac{W_{\infty}}{1+\exp (1-b(t-c))}$

Gompertz model: $W(t)=W_{\infty} \exp \left(-C e^{-K t}\right)$

where $a, Y, W_{\infty}, b, c, C$, and $K$ are constant. These equations are the same for length-based model fitting. All the parameters were determined by the least square method using the Microsoft Excel solver function. The $P$-value of $r^{2}$ and Akaike's Information Criterion (AIC) below

$$
A I C=n \ln (2 \pi)+n \ln \frac{S S}{n}+n+2(m+2)
$$

(where $S S$ is the sum of square residuals, $n$ is the sample size, and $m$ is the number of parameters) were used to evaluate and compare the fitness of the models.

Days of culture (DOC) was used rather than age for the time axis as exact information on the birth of milkfish was not available. Following the same rationale, the von Bertalanffy model, which needs to include information on the theoretical ages of the fish at their initial sizes, was not tested.

\section{Results}

\section{Fitting of growth model}

Figures 1 and 2, and Tables 2 and 3 show the model fitting results. For the logistic and Gompertz models, $r^{2}$ was higher than 0.98 , and both weight-based and lengthbased fitting were significant $(P<0.05)$ in all 14 cases, including both weight-based and length-based growth. There were nine significant cases for the linear model, which was relatively unconformable compared with the logistic and Gompertz models. Among the three models tested, the logistic model fitted best overall, with the lowest AIC and $P$-value in six out of seven cases for weight-based growth and five out of seven cases for length-based growth. AIC and $P$-values of the Gompertz model exhibited comparable or even lower values than the logistic model, particularly in length-based model fitting.

\section{Specific growth rate}

Interrelationships between $D S G R$ (of weight $D S G R_{w}$ and length $D S G R_{L}$ ) and possible parameters (ABW for $D S G R_{w}$ and $\mathrm{ABL}$ for $D S G R_{L}$, water temperature, and stocking density) were examined using multiple regression analysis. $D S G R_{w}$ and $D S G R_{L}$ were computed

Table 1. Setup specifications and details of milkfish stocking

\begin{tabular}{|c|c|c|c|c|c|c|c|}
\hline & \multirow{2}{*}{$\begin{array}{c}\text { Run } 1 \\
\text { (a) Pen } 1\end{array}$} & \multicolumn{2}{|c|}{ Run 2} & \multicolumn{2}{|c|}{ Run 3} & \multicolumn{2}{|c|}{ Run 4} \\
\hline & & (b) Pen 1 & (c) Pen 2 & (d) Pen 1 & (e) Pen 2 & (f) Pen 1 & (g) Pen 2 \\
\hline Period & $\begin{array}{l}\text { Apr. - July } \\
2016\end{array}$ & $\begin{array}{c}\text { Aug. - Dec. } \\
2016\end{array}$ & $\begin{array}{c}\text { Aug. - Dec. } \\
2016\end{array}$ & $\begin{array}{c}\text { May - July } \\
2017\end{array}$ & $\begin{array}{c}\text { May - Aug. } \\
2017\end{array}$ & $\begin{array}{c}\text { Oct. - Jan. } \\
2018\end{array}$ & $\begin{array}{c}\text { Oct. - Jan. } \\
2018\end{array}$ \\
\hline Days of culture & 95 & 108 & 108 & 54 & 96 & 91 & 91 \\
\hline Area, $\mathrm{m}^{2}$ & 144 & 150 & 162 & 150 & 162 & 150 & 162 \\
\hline Initial, pcs. & 3,354 & 3,138 & 3,712 & 3,840 & 5,498 & 4,553 & 4,760 \\
\hline $\mathrm{ABW}, \mathrm{g}$ & 39.7 & 50.5 & 47.1 & 77.2 & 27.8 & 15.8 & 16.9 \\
\hline $\mathrm{ABL}, \mathrm{cm}$ & 13.3 & 14.4 & 14.1 & 16.2 & 11.9 & 9.4 & 9.8 \\
\hline $\mathrm{CF}$ & 1.69 & 1.67 & 1.68 & 1.82 & 1.64 & 1.87 & 1.78 \\
\hline density, $\mathrm{pcs} / \mathrm{m}^{2}$ & 23.3 & 20.9 & 22.9 & 25.6 & 33.9 & 30.4 & 29.4 \\
\hline biomass, $\mathrm{g} / \mathrm{m}^{2}$ & 925 & 1,056 & 1,080 & 1,976 & 943 & 480 & 497 \\
\hline Final, pcs. & 3,321 & 3,138 & 3,687 & 3,372 & 5,405 & 4,107 & 4,655 \\
\hline recovery rate & $99 \%$ & $100 \%$ & $99 \%$ & $88 \%$ & $98 \%$ & $90 \%$ & $98 \%$ \\
\hline ABW, g & 384 & 378 & 403 & 328 & 342 & 202 & 228 \\
\hline $\mathrm{ABL}, \mathrm{cm}$ & 28 & 28 & 28 & 27 & 27 & 23 & 24 \\
\hline $\mathrm{CF}$ & 1.68 & 1.77 & 1.78 & 1.63 & 1.66 & 1.74 & 1.74 \\
\hline total biomass, $\mathrm{kg}$ & 1,275 & 1,187 & 1,485 & 1,106 & 1,846 & 832 & 1,062 \\
\hline biomass, $\mathrm{g} / \mathrm{m}^{2}$ & 8,855 & 7,913 & 9,164 & 7,373 & 11,398 & 5,543 & 6,554 \\
\hline FCR & 2.23 & 2.90 & 2.87 & 2.44 & 2.37 & 2.59 & 2.49 \\
\hline
\end{tabular}

Run 1 and Run 3 correspond to the dry season; Run 2 and Run 4 correspond to the rainy season. 
between every sampling, and $\mathrm{ABW}$ and $\mathrm{ABL}$ were obtained from the precedent sampling $(t 1)$.

The variables were standardized to compare the contribution of each parameter expressed in different units:

$$
D S G R_{w}{ }^{\prime}=\beta_{1} X_{1}{ }^{\prime}+\beta_{2} X_{2}{ }^{\prime}+\ldots \ldots
$$

where $\beta_{1}$ and $\beta_{2}$ are the linear regression coefficients, and $X_{1}^{\prime}$ and $X_{2}^{\prime}$ are standardized variables. Table 4 shows the statistical parameters of multiple regression analysis. Based on pre-analysis, the stocking density was determined to be not significant $(P>0.05)$ for both $D S G R_{w}$ and $D S G R_{L}$. Therefore, ABW and water temperature were used for $D S G R_{w}$, and $\mathrm{ABL}$ and water temperature were used to predict $D S G R_{L}$. ABW was shown to be a dominant variable having a negative correlation with $D S G R_{w}$. Water temperature was positively correlated with $D S G R_{w}$, but the contribution was relatively weak compared with ABW. A similar relationship to a comparable degree was found between $D S G R_{L}$ and $\mathrm{ABL}$ and water temperature.

\section{Condition factor}

Figure 3 plots the condition factor (CF) of all sampled fish against ABW $(\mathrm{n}=1,509$ in the dry season and $n=1,208$ in the rainy season). The Standard deviation (SD) of CF of the fish decreased as the fish grew and converged to 0.09 (Figs. 3 \& 4). This suggests that $\mathrm{CF}$ values at the final sampling should be used to compare the differences in such factors as environmental conditions. The differences in CF between the dry season and rainy season were compared by the $t$-test and the difference was found to be highly significant $(P<0.0001)$. However, a positive correlation was also found to be significant between the feed conversion ratio (FCR) and
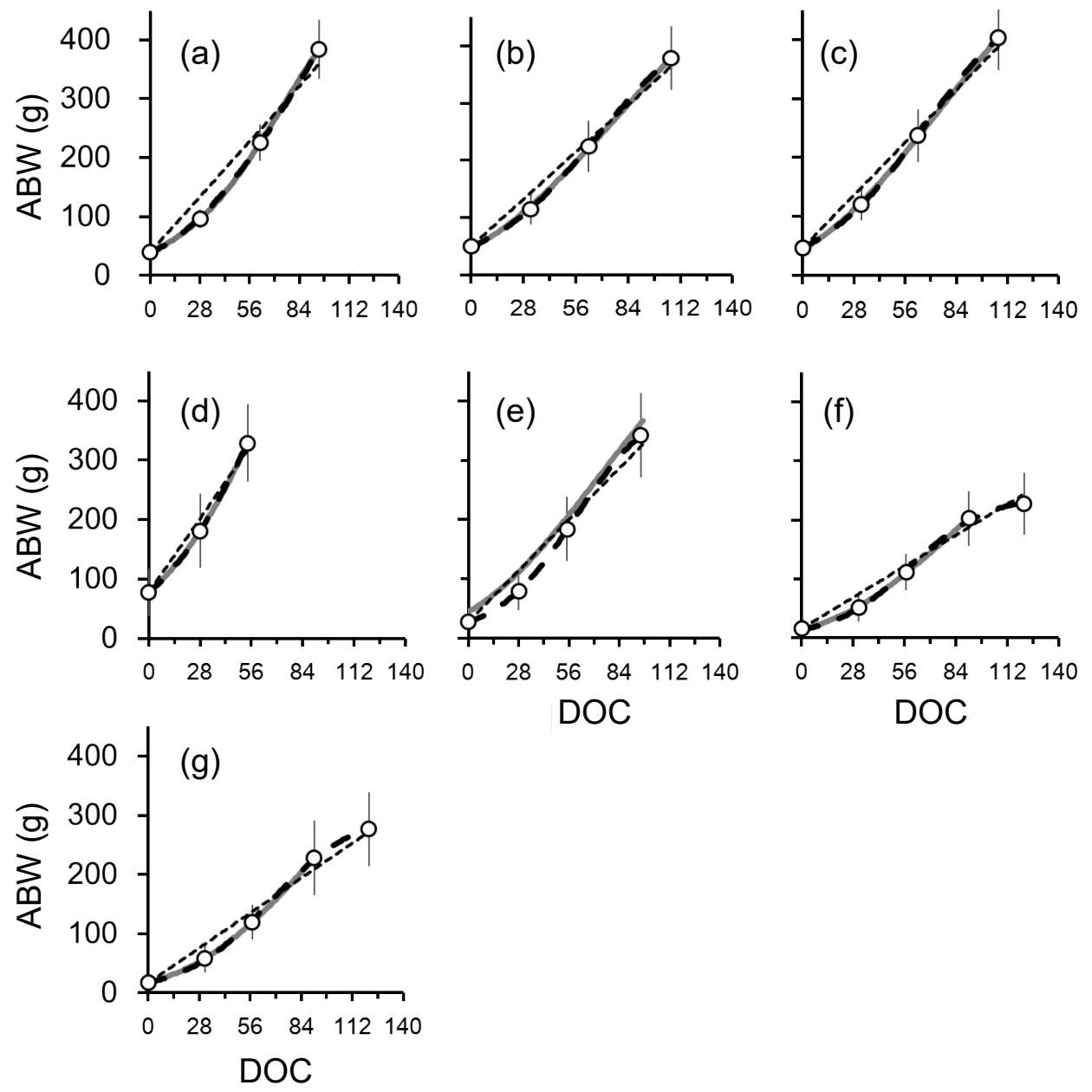

Fig. 1. Fitting of growth models in average body weight (ABW) Open circles indicate measured value with standard deviation, the black dotted line indicates the linear model, the black dashed line indicates the logistic model, and the gray solid line indicates the Gompertz model. (a), (d) and (e) correspond to the dry season; (b), (c), (f) and (g) correspond to the rainy season. See Table 1 for the Run and Pen specifications. 

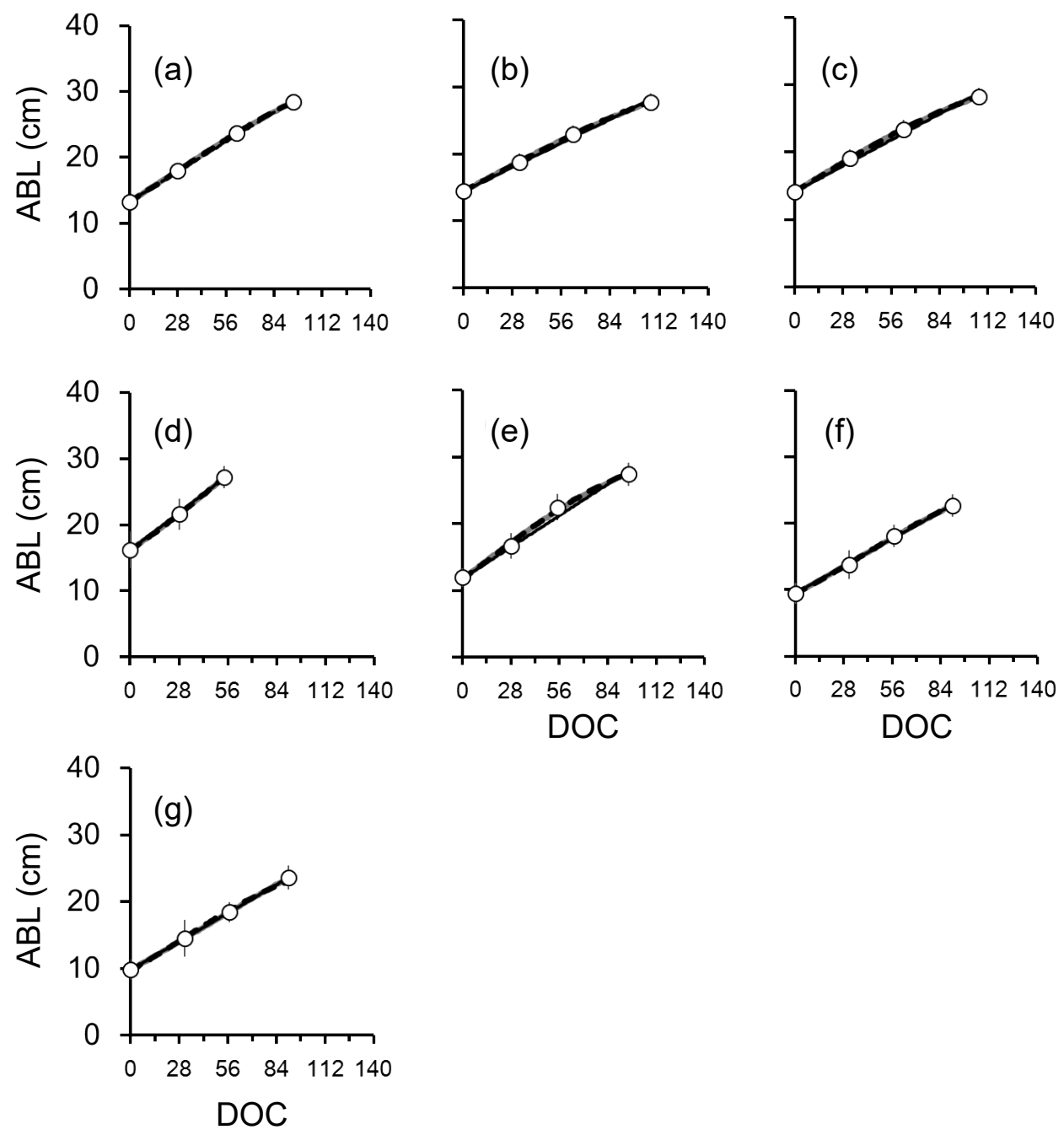

Fig. 2. Fitting of growth models in length

Open circles indicate measured value with standard deviation, the black dotted line indicates the linear model, the black dashed line indicates the logistic model, and the gray solid line indicates the Gompertz model. (a), (d) and (e) correspond to the dry season; (b), (c), (f) and (g) correspond to the rainy season. See Table 1 for the Run and Pen specifications.

Table 2. Fitting of growth models across average body weight (ABW)

\begin{tabular}{|c|c|c|c|c|c|c|c|c|}
\hline \multirow{3}{*}{ model } & \multirow{3}{*}{ indicator } & \multirow{3}{*}{$\begin{array}{c}\text { Run } 1 \\
\text { Pen } 1 \\
\text { n=4 }\end{array}$} & \multicolumn{2}{|c|}{ Run 2} & \multicolumn{2}{|c|}{ Run 3} & \multicolumn{2}{|c|}{ Run 4} \\
\hline & & & Pen 1 & Pen 2 & Pen 1 & Pen 2 & Pen 1 & Pen 2 \\
\hline & & & $n=4$ & $\mathrm{n}=4$ & $n=3$ & $n=4$ & $\mathrm{n}=4$ & $\mathrm{n}=4$ \\
\hline \multirow{3}{*}{ Linear } & AIC & 363.6 & 347.3 & 347.3 & 340.3 & 355.2 & 262.4 & 269.7 \\
\hline & $r^{2}$ & 0.987 & 0.994 & 0.995 & 0.992 & 0.990 & 0.999 & 0.996 \\
\hline & Pvalue & 0.05265 & 0.03736 & 0.03465 & 0.18297 & 0.04647 & 0.05798 & 0.11435 \\
\hline \multirow{3}{*}{ Logistic } & AIC & 131.0 & 163.5 & 144.0 & 120.0 & 147.9 & 125.2 & 179.5 \\
\hline & $r^{2}$ & 1.000 & 1.000 & 1.000 & 1.000 & 1.000 & 1.000 & 1.000 \\
\hline & $P$ value & 0.00090 & 0.00312 & 0.00158 & 0.00264 & 0.00200 & 0.00106 & 0.00746 \\
\hline \multirow{3}{*}{ Gompertz } & AIC & 184.0 & 209.7 & 193.6 & 123.0 & 227.7 & 170.4 & 132.2 \\
\hline & $r^{2}$ & 1.000 & 1.000 & 1.000 & 1.000 & 0.999 & 1.000 & 0.997 \\
\hline & Pvalue & 0.00508 & 0.01044 & 0.00644 & 0.02105 & 0.01685 & 0.00661 & 0.00162 \\
\hline
\end{tabular}

Values highlighted in bold indicate the smallest values among the comparison of three models. Run 1 and Run 3 correspond to the dry season; Run 2 and Run 4 correspond to the rainy season. 
CF $\left(r^{2}=0.919, P=0.00065\right)$. Both values (FCR and CF) are smaller in the dry season $(\mathrm{FCR}=2.21, \mathrm{CF}=1.64 \pm$ $0.14)$ and larger in the rainy season $(\mathrm{FCR}=2.71, \mathrm{CF}=$ $1.73 \pm 0.15$ ) (Fig. 5). The contribution of variables $S G R_{w}$, $S G R_{L}$, total biomass of the stock, and water temperature to $\mathrm{CF}$ were examined (Table 5). Based on this first assessment, the contributions of $S G R_{w}$ and biomass were not statistically significant $(P$-values were 0.0523 and 0.943 , respectively). Hence, the multiple regression model was only applied to two variables, $S G R_{L}$ and water temperature, wherein both variables were negatively correlated with $\mathrm{CF}$ at a comparable magnitude to distribution (Table 6).

\section{Discussion}

\section{Validity of model fitting}

It has been well-documented since the early 20th century that the growth performance and body composition of fish vary along life cycle stages, and are affected by endogenous and exogenous factors such as genetic strain, environmental conditions, feed composition, and culture management. As exhibited in the evaluation of model fitting, the two sigmoidal logistic and Gompertz models have simulated actual measurements more accurately than the linear model (Tables $2 \& 3$ ). In the weight-based growth model fitting, the linear model tends to overestimate growth during the early period (from around 4 to 8 weeks) and underestimate growth after 16 weeks; however, this trend is not clear in the length-based model. This is probably because the milkfish examined in this study were in the juvenile stage, far from maturation. Milkfish mature sexually in 5 years and reach an average body weight of at least $1.5 \mathrm{~kg}$ (FAO, Cultured Aquatic Species Information Programme). In addition, the minimal mature age of milkfish in captivity was 5 years for males and 6 years for females (Lee 1995), and that the minimal size for maturation should be $3 \mathrm{~kg}$ or more (Lee et al. 1986b). Moreover, milkfish that were reared from wild-caught fry and hatchery bred fry matured at 3.5 to 5.5 years with the size of $2.3 \mathrm{~kg}-4.9 \mathrm{~kg}$ (Marte \& Lacanilao 1986). In the juvenile stage, carcass growth is faster than weight gain, which is common in fish, aquatic organisms, as well as terrestrial animals (Oikawa \& Itazawa 1984). Therefore, it is reasonable to simulate the growth of milkfish with sigmoidal models for this size range.

Table 3. Fitting of growth models across average body length (ABL)

\begin{tabular}{|c|c|c|c|c|c|c|c|c|}
\hline \multirow{3}{*}{ model } & \multirow{3}{*}{ indicator } & \multirow{3}{*}{$\begin{array}{c}\text { Run } 1 \\
\text { Pen } 1 \\
n=4\end{array}$} & \multicolumn{2}{|c|}{ Run 2} & \multicolumn{2}{|c|}{ Run 3} & \multicolumn{2}{|c|}{ Run 4} \\
\hline & & & Pen 1 & Pen 2 & Pen 1 & Pen 2 & Pen 1 & Pen 2 \\
\hline & & & $\mathrm{n}=4$ & $\mathrm{n}=4$ & $\mathrm{n}=3$ & $\mathrm{n}=4$ & $\mathrm{n}=4$ & $\mathrm{n}=4$ \\
\hline \multirow{3}{*}{ Linear } & AIC & 205.5 & 209.1 & 218.3 & 202.6 & 228.0 & 124.3 & 120.1 \\
\hline & $r^{2}$ & 0.999 & 0.998 & 0.996 & 0.999 & 0.993 & 0.999 & 1.000 \\
\hline & P value & 0.01298 & 0.01951 & 0.02844 & 0.09459 & 0.03894 & 0.01381 & 0.00294 \\
\hline \multirow{3}{*}{ Logistic } & AIC & 120.0 & 120.1 & 120.3 & 120.0 & 129.7 & 121.4 & 129.8 \\
\hline & $r^{2}$ & 1.000 & 1.000 & 1.000 & 1.000 & 0.999 & 1.000 & 0.998 \\
\hline & $P$ value & 0.00066 & 0.00165 & 0.00318 & 0.00209 & 0.01850 & 0.00758 & 0.02035 \\
\hline \multirow{3}{*}{ Gompertz } & AIC & 120.4 & 120.4 & 120.0 & 120.0 & 133.2 & 122.6 & 120.5 \\
\hline & $r^{2}$ & 1.000 & 1.000 & 1.000 & 1.000 & 0.998 & 1.000 & 1.000 \\
\hline & Pvalue & 0.00362 & 0.00398 & 0.00014 & 0.02208 & 0.02255 & 0.01050 & 0.00443 \\
\hline
\end{tabular}

Values highlighted in bold indicate the smallest values among the comparison of three models. Run 1 and Run 3 correspond to the dry season; Run 2 and Run 4 correspond to the rainy season.

Table 4. Statistical parameters of multiple regression analysis for DSGRw and DSGRL $(n=22)$

\begin{tabular}{|c|c|c|c|c|c|}
\hline$D S G R_{w}$ & $\beta_{1}$ & $\beta_{2}$ & $D S G R_{L}$ & $\beta_{1}$ & $\beta_{2}$ \\
\hline slope & -0.740 & 0.383 & slope & -0.716 & 0.391 \\
\hline$P$ & $1.57 \times 10^{-6}$ & $2.39 \times 10^{-3}$ & $P$ & $3.56 \times 10^{-6}$ & $2.51 \times 10^{-3}$ \\
\hline$R^{2}$ & \multicolumn{2}{|c|}{0.760} & $R^{2}$ & \multicolumn{2}{|c|}{0.750} \\
\hline
\end{tabular}

$\beta 1$ and $\beta 2$ are the coefficient (slope) of ABW or ABL and water temperature, respectively. 


\section{Variation in growth rate and condition factor}

The analysis results showed that the daily growth rate in both weight and length $\left(D S G R_{w}\right.$ and $\left.D S G R_{L}\right)$ depends on the size of fish; thus, as the fish grows, the growth rate decreases (Table 4). This is reasonable and consistent with the theory of common animal growth, where body size is the most important factor determining the rate of processes. The theory on animals of different body sizes where the metabolic rate is proportional to their respective surface areas is called the surface law of metabolism. The weight-specific metabolic rate decreases with increasing body size; however, several metabolic types with respect to the relation between metabolic rate and body size exist in different species of animals based on their physiological characteristics. In relation, as different metabolic types exist, different growth types also prevail as distinguished by the course of growth expressed in the growth curve of various species. (Kleiber 1947, von Bertalanffy 1957). Particularly for most fish species, von Bertalanffy's growth equation is widely used and according to von Bertalanffy (1957), as long as the animal is small, the surface-proportional anabolism prevails over weight-proportional catabolism in growth, and the larger it grows, the remaining surplus for growth decreases and a steady state will be eventually reached where anabolism and catabolism balance each other and
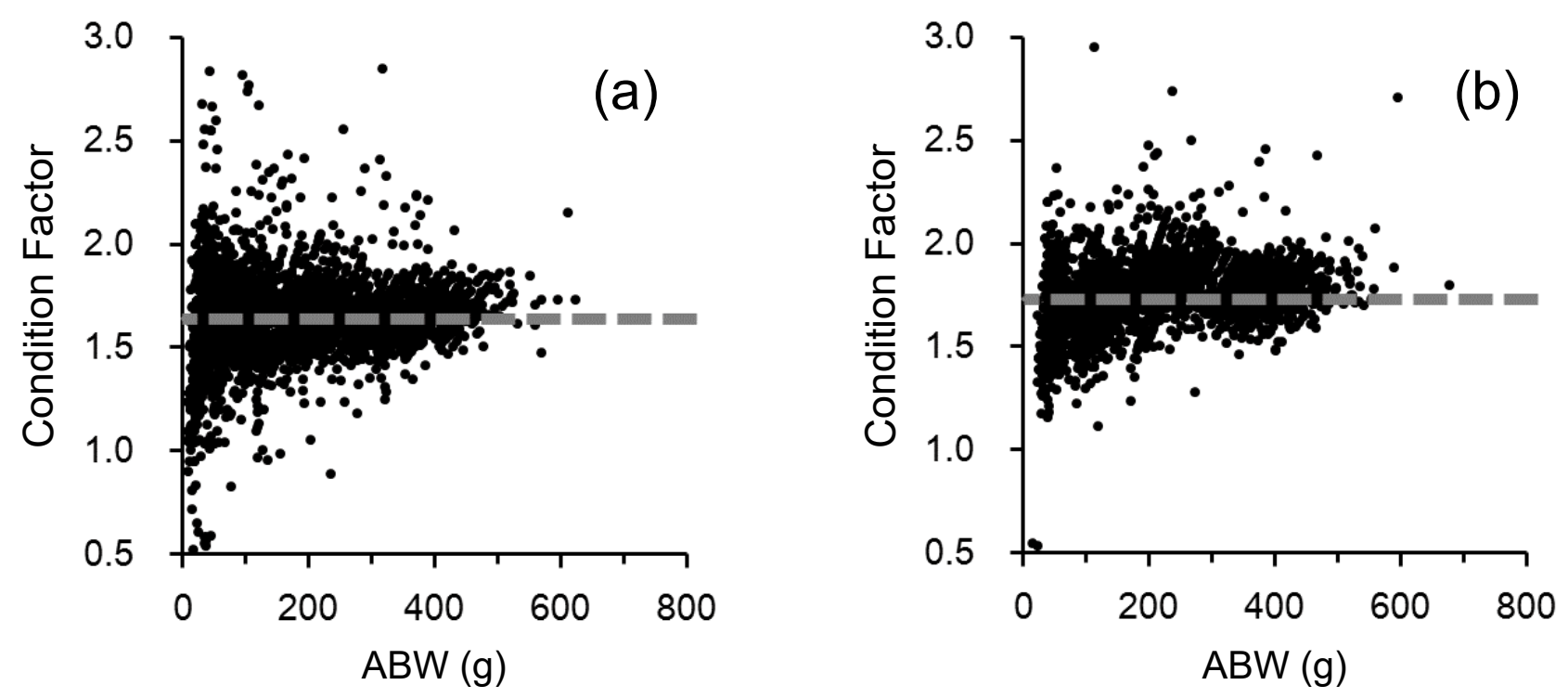

Fig. 3. Condition factor of all sampled fish

(a) dry season and (b) rainy season. Gray dashed lines indicate mean values of the dry season $(=1.64)$ and rainy season (=1.73), respectively.

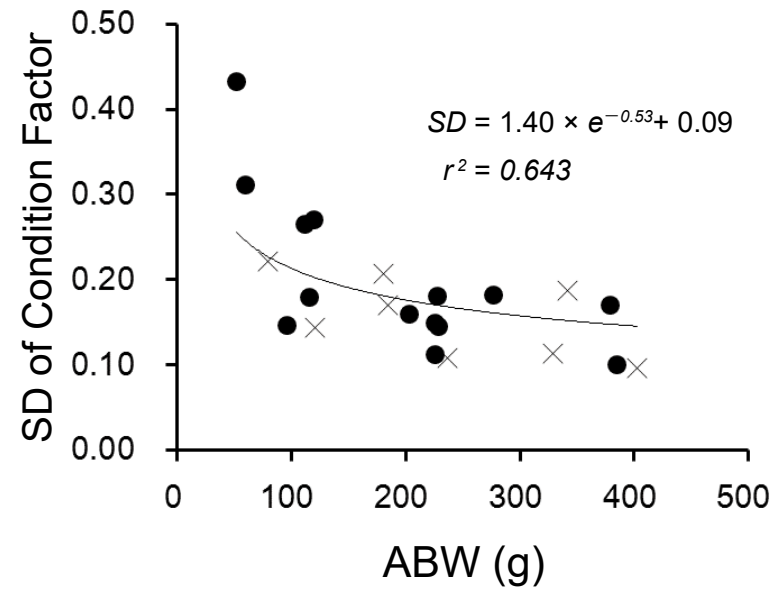

Fig. 4. Standard deviation (SD) of condition factor (CF) at each sampling in the dry season $(\times)$ and rainy season (•)

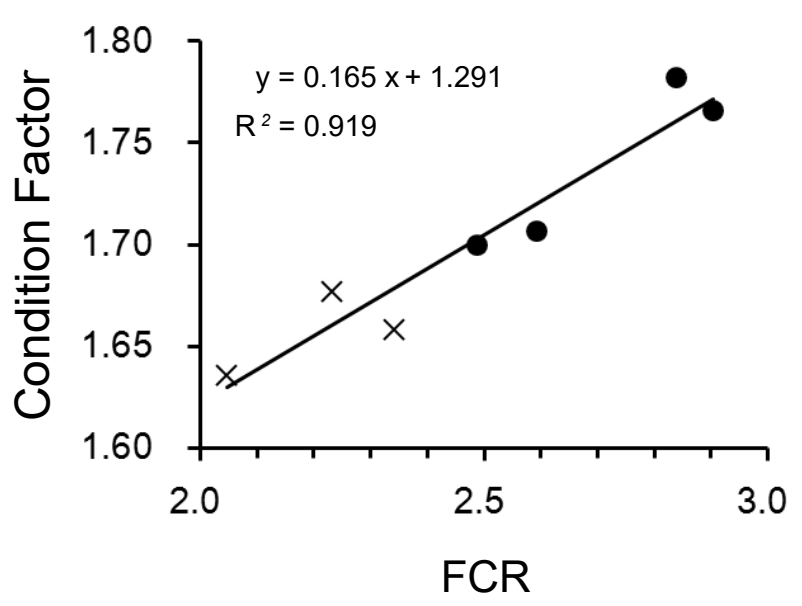

Fig. 5. Relationship between feed conversion ratio (FCR) and condition factor $(C F)$ in the dry season $(x)$ and rainy season (•) 
growth ends. This could also support the findings that sigmoidal models fit well, as previously discussed. Although the negative correlation between condition factor (CF) and $S G R_{L}$ is logical, the negative correlations between $\mathrm{CF}$ and water temperature, and positive correlations between feed conversion ratio (FCR) and CF found in this study seem controversial (Table 6 \& Fig. 5). These relationships suggest that low temperature and inefficient feeding lead to 'fat' fish and vice versa. These controversial findings could be explained by two aspects of fish biology. One is the relationship between $\mathrm{CF}$ and body composition, and the other is size and the temperature-dependent metabolism of fish. CF of fish is also influenced by body composition, including the water, fat, lipid, and protein contents of the fish. As the density of protein is higher than density of water, fat and lipid, protein-rich fish of the same length become heavier and $\mathrm{CF}$ also becomes larger.

\section{1 Condition factor and body composition}

A negative correlation between condition factor (CF) and water percentage, and an inverse relationship with protein were reported for the northern pike Esox Lucius L (Salam \& Davies 1994); a similar result was seen for the tropical cichlid (Tilapia rendalli Boulenger), where the lowest ratio of water was found in the tissue of fish with high CF (Caulton 1978). In small catfish (Mystus bleekeri), the percentage of fat, protein, and organic contents showed an inverse relationship with water percentage in wet body weight (Naeem \& Ishtiaq 2011), whereas in rainbow trout (Salmo gairdneri), the percentage of protein increased as the fish grew, particularly in the early stages (Reinitz 1983). These findings are from different sources and a mixture of carnivorous and omnivorous species in various

Table 5. Examined variables for multiple regression analysis of condition factor (CF)

\begin{tabular}{lcccc}
\hline \hline & $\begin{array}{c}S G R_{w} \\
(\% / \text { day })\end{array}$ & $\begin{array}{c}S G R_{L} \\
(\% / \text { day })\end{array}$ & $\begin{array}{c}\text { Temperature } \\
\left({ }^{\circ} \mathrm{C}\right)\end{array}$ & $\begin{array}{c}\text { Biomass } \\
\left(\mathrm{kg} / \mathrm{m}^{2}\right)\end{array}$ \\
\hline Run 1 \& 3 & 9.0 & 1.3 & 30.8 & 1,509 \\
Run 2 \& 4 & 10.0 & 1.2 & 29.2 & 1,208 \\
\hline
\end{tabular}

Table 6. Statistical parameters of multiple regression analysis for condition factor $(n=7)$

\begin{tabular}{|c|c|c|}
\hline$C F$ & $\beta_{1}$ & $\beta_{2}$ \\
\hline slope & -0.902 & -0.797 \\
\hline$P$ & $1.12 \times 10^{-3}$ & $1.95 \times 10^{-3}$ \\
\hline$R^{2}$ & & \\
\hline
\end{tabular}

$\beta 1$ and $\beta 2$ are the coefficient (slope) of SGRL and water temperature, respectively. conditions. As no data was obtained for the proximate body compositions of the milkfish used in this study, we can speculate that the fish with high CF (slow growth and low FCR) in this study were high in protein and low in water content.

\section{2 Temperature, growth, and protein content}

Several studies on the relationship between temperature, growth, and protein content were reported. In juvenile European seabass (Dicentrarchus labrax), the growth and feed efficiency were significantly higher at higher temperatures, but protein utilization was more efficient at lower temperatures (Peres \& Oliva-Teres 1999). Similarly, Gill \& Weatherley (1984) suggested that the bluntnose minnow (Pimephales notatus) raised at low temperatures had significantly higher levels of body protein.

In summary, the slow growth of fish caused by low temperatures may lead to a low metabolic rate and high FCR results with high protein content. Similar relationships were reported by several authors for various kinds of fish species, including sockeye salmon (Oncorhynchus nerka; Brett et al. 1969, Groves 1970), brown trout (Salmo trutta L.; Elliot 1976), rainbow trout (Oncorhynchus mykiss; Dumas et al. 2007), striped jack (Pseudocaranx dentex; Nakajima et al. 1995), and Atlantic silverside (Menidia menidia; Schultz \& Conover 1997), which might be applicable to this study.

\section{3 Effect of metabolic rate in relation to fish size}

It is well-known that small (young) fish have higher weight-specific metabolic rates than adults (Jobling 1981, Handy \& Poxton 1993). For milkfish, it was reported that small fish excreted a significantly higher percentage of ammonium nitrogen from consumed feed than that excreted by bigger fish (Sumagaysay-Chavoso 2003), which suggests that the deposition of protein is lower in relatively smaller fish than that in bigger fish. As the protein requirement is generally higher for smaller fish that have a higher metabolic rate than larger fish, they consequently have a high energy demand. Therefore, it is possible that smaller fish use protein to generate energy instead of it being converted into body protein, and this protein catabolism would lead to an increase in ammonia excretion. Besides, protein intake and ammonia excretion in fish have been found to be directly related ( $\mathrm{Li} \&$ Lovell 1992, Chakraborty \& Chakraborty 1998, Leung et al. 1999). A similar observation was also documented for other species such as gilthead seabream (Porter et al. 1987), areolate grouper, and mangrove snapper (Leung et al. 1999). The integration of these studies could support the results of the present study: bigger fish grow more slowly than smaller fish (Table 4) and CF is negatively correlated with growth rate (Table 6). 
Although the current study is limited to a narrow range of conditions, such as the life stage of the fish, design of the culturing facility, climate, and location, findings in this study may provide useful information for milkfish culturing as this is the first study to present a nonlinear model for milkfish growth in marine pens, as well as cage and pond culturing. Further studies that cover the complete life cycles of milkfish and a wide range of environmental conditions may contribute to better practices through improved estimations of feed allocation. The outputs of the models could also be utilized to diagnose health conditions of the fish or proximate body composition by comparing expected growth and the actual situations. Additional studies and the integration of scattered information, particularly focused on relationships between growth performance and body composition under various conditions, are expected to help elucidate the characteristics and features of milkfish, and thus improve the industry.

\section{Acknowledgements}

This study was funded by the Japan International Research Center for Agricultural Sciences (JIRCAS) research project, "Development of Technologies for Sustainable Aquatic Production in Harmony with Tropical Ecosystems." We are grateful to the Local Government Unit of Baranggay Pandaraonan, Nueva Valencia Guimaras, and the fisherfolk members of the Pandaraonan Unified Association (PUA) for research collaboration.

\section{References}

Bagarinao, T. U. (1991) Biology of milkfish (Chanos chanos Forsskal). Tigbauan, Iloilo, Philippines: SEAFDEC Aquaculture Department.

Biswas, G. et al. (2011) Length-weight relationship and variation in condition of Chanos chanos (Forsskål, 1775) from tide-fed brackish water ponds of the Sunderbans - India. Indian J. Geo-Mar. Sci., 40, 386-390.

Brett, J. R. et al. (1969) Growth rate and body composition of fingerling sockeye salmon, Oncorhynchus nerka, in relation to temperature and ration size. J. Fish. Res. Board Can., 26, 2363-2394.

Caulton, M. S. (1978) The importance of habitat temperature for growth in the tropical cichlid Tilapia rendalli Boulenger. J. Fish Biol., 13, 99-122.

Chakraborty, S. C. \& Chakraborty, S. (1998) Effect of dietary protein level on excretion of ammonia in Indian major carp, Labeo rohita, fingerlings. Aquacult. Nut., 4, 46-51.

Dumas, A. et al. (2007) Quantitative description of body composition and rates of nutrient deposition in rainbow trout (Oncorhynchus mykiss). Aquaculture, 273, 165-181.

Dumas, A. et al. (2010) Modelling growth and body composition in fish nutrition: where have we been and where are we going? Aquaculture Research, 41, 161-181. https:// doi:10.1111/j.1365-2109.2009.02323.x.

Elliott, J. M. (1976) Body composition of brown trout (Salmo trutta L.) in relation to temperature and ration size. J. Anim. Ecol., 45, 273-289.

FAO. Chanos chanos (Forsskal, 1775), Cultured Aquatic Species Information Programme. http://www.fao.org/fishery/ culturedspecies/Chanos_chanos/en. Accessed 8 June 2020.

FAO. Milkfish-Growth, Aquaculture Feed and Fertilizer Resources Information System. http://www.fao.org/fishery/affris/speciesprofiles/milkfish/growth/en. Accessed 11 November 2019.

Fisheries Statistics of the Philippines, Philippine Statistics Authority 2015-2017. https://psa.gov.ph/sites/default/files/FSP\% 202015-2017.pdf.

Gill, H. S. \& Weatherley, A. H. (1984) Protein, lipid and caloric contents of bluntnose minnow, Pimephales notatus Rafinesque, during growth at different temperatures. Fish Biology, 25, 491-500. https://doi.org/10.1111/j.1095-8649. 1984.tb04895.x.

Groves, T. D. D. (1970) Body composition changes during growth in young sockeye (Oncorhynchus nerka) in fresh water. J. Fish. Res. Bd. Can., 27, 929-42.

Handy, R. D. \& Poxton, G. (1993) Nitrogen pollution in mariculture: toxicity and excretion of nitrogenous compounds by marine fish. Reviews in Fish Biology and Fisheries, 3, 205-241.

Hanke, I. et al. (2019) Thermal stress response of juvenile milkfish (Chanos chanos) quantified by ontogenetic and regenerated scale cortisol. Aquaculture, 500, 24-30. https:// doi.org/10.1016/j.aquaculture.2018.09.016.

Hossain, M. Y. et al. (2006) Condition, length-weight and length-length relationships of the Asian striped catfish Mystus vittatus (Bloch, 1794) (Siluriformes: Bagridae) in the Mathabhanga River, southwestern Bangladesh. J. Appl. Ichthyol., 22, 304-307.

Jobling, M. (1981) Some effects of temperature, feeding and body weight on nitrogenous excretion in young plaice Pleuronectes platessa L. Fish Biology, 18, 87-96. https:// doi.org/10.1111/j.1095-8649.1981.tb03763.x.

Kleiber, M. (1947) Body size and metabolic rate. Physiol. Rev., 27, 511-541.

Lee, C. S. (1995) Aquaculture of milkfish (Chanos chanos). TML Aquaculture Series, 1, Tungkang Marine Laboratory, Taiwan Fisheries Research Institute, Taiwan.

Lee, C. S. et al. (1986) Influence of chronic administration of LHRH-analogue and/or $17 \alpha$-methyltestosterone on maturation in milkfish, Chanos chanos. Aquaculture, 59, 147-159.

Leung, K. M. Y. et al.(1999) Effects of body weight, water temperature and ration size on ammonia excretion by the areolate grouper (Epinephelus areolatus) and mangrove snapper (Lutjanus argentimaculatus). Aquaculture, 170, 215-227.

Li, M. \& Lovell, R. T. (1992) Effect of dietary protein concentration on nitrogenous waste in intensively fed catfish ponds. J. World Aquacult. Soc., 23, 122-127.

Marte, C. L. \& Lacanilao, F. J. (1986) Spontaneous maturation and spawning of milkfish in floating net cages. Aquaculture, 53, 115-132.

Naeem, M. \& Ishtiaq, A. (2011) Proximate composition of 
Mystus bleekeri in relation to body size and condition factor from Nala Daik, Sialkot, Pakistan. African Journal of Biotechnology, 10, 10765-10763.

Nakajima, M. et al. (1995) Effect of Growth Rate and Fish Size Selection on Body Composition in Striped Jack, Pseudocaranx dentex Fingerlings. SUISANZOSHOKU, 43, 353-358 [In Japanese with English abstract].

Oikawa, S. \& Itazawa, W. (1984) Relative growth of organs and parts of the carp, Cyprinus carpio, with special reference to the metabolism-size relationship. Copeia, 3, 800-803.

PAGASA, Philippine Atmospheric, Geophysical and Astronomical Services Administration, Department of Science and Technology. Climate of the Philippines. http://bagong.pagasa.dost.gov. $\mathrm{ph} /$ information/climate-philippines. Accessed 8 June 2020.

Pauly, D. et al. (1993) Multiple regression analysis of aquaculture experiments based on "Extended Gulland-and-Holy Plos": Model derivation, data requirements and recommended procedure. 13-23. In M. Prein, G. Hulata \& D. Pauly (eds.), Multivariate methods in aquaculture research: case studies of tilapias in experimental and commercial systems, ICLARM Studies and Reviews, 20.

Peres, H. \& Oliva-Teles, A. (1999) Influence of temperature on protein utilization in juvenile European seabass (Dicentrarchus labrax). Aquaculture, 170, 337-348.

Porter, C. B. et al. (1987) Ammonia excretion and total N budget for gilthead seabream (Sparus aurata) and its effect on water quality conditions. Aquaculture, 66, 287-297.

Reinitz, G. (1983) Relative effect of age, diet, and feeding rate on the body composition of young rainbow trout (Salmo gairdneri). Aquaculture, 35, 19-27.

Rogers-Bennet, L. et al. (2007) Modeling growth and mortality of red abalone (Haliotis rufescens) in Northern California. J. Shellfish Research, 26, 719-727.

Salam, A. \& Davies, P. M. C. (1994) Body composition of northern pike, Esox lucius L. in relation to body size and condition factor. Fish. Res., 19, 193-204.

Schultz, E. T. \& Conover, D. O. (1997) Latitudinal differences in somatic energy storage: adaptive responses to seasonality in an estuarine fish (Atherinidae: Menidia menidia). Oecologia, 109, 516-529.

Sumagaysay, N. S. (1994) Growth and food consumption of milkfish (Chanos chanos) during dry and wet seasons. International Journal of Tropical Agriculture, 12, 1-11.

Sumagaysay-Chavoso, N. S. (2003) Nitrogen and phosphorus digestibility and excretion of different-sized groups of milkfish (Chanos chanos Forsskal) fed formulated and natural food-based diets. Aquaculture Research, 34, 407-418.

von Bertalanffy, L. (1957) Quantitative laws in metabolism and growth. Quarterly Reviews of Biology, 32, 217-231.

Watanabe, S. et al. (2014) Growth Pattern of Tropical Sea Cucumber, Holothuria scabra, under captivity. JARQ, 48, 457-464.

Weatherley, A. H. \& Gill, H. S. (1987) The Biology of Fish Growth. Academic Press, London. 